\title{
O PÓS-ESTRUTURALISMO E O DEBATE SOBRE A FABRICAÇÃO DOS SUJEITOS: A GENEALOGIA DE MICHEL FOUCAULT
}

\author{
Gilberto Antes ${ }^{1}$ \\ Eduardo Nunes Jacondino ${ }^{2}$
}

\begin{abstract}
RESUMO: Este artigo apresenta uma discussão acerca da perspectiva pósestruturalista, seus métodos e os novos questionamentos sociais que têm se consolidado no presente. O pós-estruturalismo apresenta novas possibilidades de compreensão da realidade social, em especial no que se refere a produção dos sujeitos, por meio das relações de poder e da relação poder-saber, consolidada a partir de dispositivos institucionais que objetivam a fabricação dos sujeitos. Busca-se descrever de que modo as novas identidades se consolidam. Nesta busca, a obra de Michel Foucault oferece importantes contribuições, ao se livrar da ideia da existência de uma verdade final a ser atingida, tal qual propuseram as grandes metanarrativas iluministas. Foucault entende que os sujeitos são fabricados por meio de processos sociais, através de dispositivos e instituições; bem como por meio das relações de poder-saber. Para isso, Foucault, por meio da genealogia desceu aos porões da história para compreender como estes discursos que produzem formas de ser e agir.
\end{abstract}

Palavras-chave: Sujeito; Fabricação; Pós-estruturalismo.

\section{POST-STRUCTURALISM AND THE DEBATE ON THE MANUFACTURE OF SUBJECTS: THE GENEALOGY OF MICHEL FOUCAULT}

\begin{abstract}
This article presents a discussion about the post-structuralist perspective, its methods and the new social questions that have been consolidated in the present. Post-structuralism presents new possibilities for understanding social reality, especially with regard to the production of subjects, through power relations and the powerknowledge relationship, consolidated from institutional devices that aim at the manufacture of subjects. It seeks to describe how the new identities are consolidated. In this search, Michel Foucault's work offers important contributions, in getting rid of the idea of the existence of a final truth to be attained, as proposed by the great Enlightenment meta-narratives. Foucault understands that subjects are manufactured through social processes, through devices and institutions; as well as through powerknowledge relationships. For this, Foucault, through genealogy, went down to the basements of history to understand how these discourses produce ways of being and acting.
\end{abstract}

Keywords: Subject; Manufacturing; Post-structuralism.

\footnotetext{
${ }^{1}$ Professor, Mestrando no Programa de Pós-Graduação em Educação da Universidade Estadual do Oeste do Paraná (UNIOESTE). E-mail: professor.giba@hotmail.com

2 Professor, Doutor, na Universidade Estadual do Oeste do Paraná (UNIOESTE). E-mail: eduardojacondino@hotmail.com
}

Programas de Pós-Graduação em Ciências Sociais e Filosofia - UNIOESTE - Rua da

Faculdade 645. Toledo - PR. CEP 85.903-000 Email: revistaalamedas@gmail.com 


\section{INTRODUÇÃO}

O presente artigo apresenta um pequeno apanhado metodológico sobre a corrente pós-estruturalista. Apresenta uma discussão sobre as novas formas de olhar e compreender a produção das identidades - dos sujeitos - em especial a partir da obra de Michel Foucault.

A nova realidade social, política, econômica e cultural exige que novas formas de compreensão sejam pensadas. As recentes transformações sociais vêm provocando profundas transformações nas formas dos sujeitos se relacionarem. Até a década de 1960 os olhares voltados ao social restringiam-se a forma estruturalista, seguindo algumas premissas; fixadas em algumas ideias. Ideias como a da existência de um progresso linear - sócio histórico - e a da existência de padrões universais de racionalidade. O pós-estruturalismo nasce como forma de questionar este tipo de olhar. Olhar centrado, até então, numa pretensa estrutura, estável e autorreferente.

O pós-estruturalismo passa a buscar uma compreensão que supere este olhar anterior, voltado ao entendimento das realidades sociais. Busca olhar para 'um novo mundo' - do ponto de vista cultural, notadamente - que se apresenta a partir da década de 1960. Mundo caracterizado pelo fim da chamada guerra fria e pela entrada no processo que fica conhecido como globalização.

O pós-estruturalismo lança um olhar com o objetivo de compreender as novas identidades que passam a se constituir frente a estas transformações. Para isso, se ancora na obra de autores como Friedrish Nietzsche e Martin Heidegger. Faz novas perguntas, busca desenvolver novos métodos de análise (arqueologia, genealogia, esquizoanálise, desconstrução, etc) com a intensão de desenvolver novas perspectivas analíticas, para ir além daquelas oferecidas até então.

Neste percurso a obra de Michel Foucault oferece importantes contribuições para se compreender a construção/fabricação destas novas identidades e o processo social de produção dos sujeitos; através das relações de poder-saber que se institucionalizam, formando campos discursivos e tecnologias sociais.

Foucault livra-se da ilusão de que há uma verdade final a ser atingida - do ponto de vista ontológico e histórico - e dá às costas para as grandes metanarrativas 
que, desde o iluminismo, propõem a existência de um sujeito universal. Para Foucault os sujeitos são produzidos por meio de processos sociais, por dispositivos estrategicamente pensados e institucionalizados, por meio dos quais saberes e tecnologias sociais - os poderes em ação - subjetivam os indivíduos. Produzindo, nestes, formas de ser e agir.

Para consolidar esta construção Foucault buscou superar as grandes metanarrativas: Religiosas, políticas e jurídicas. Mostrando como estes discursos consolidaram-se ao longo do tempo e quais as estratégias micropolíticas foram utilizadas, em paralelo, de modo a 'produzir' determinados tipos de sujeito.

Para autores como Foucault as sociedades modernas apresentam-se como sociedades permeadas por padrões de comportamento - processos de normalização que se consolidam através de discursos sociais. Discursos que, por sua vez, são fruto de relações de poder e das respectivas tecnologias sociais - notadamente, os dispositivos que agem sobre os sujeitos, produzindo-os em determinadas direções - ancoradas em formas de ser e agir. Formas, entretanto, que não eliminam Mas Compreender como este processo ocorre é a intenção de autores como Foucault.

\section{O PÓS-ESTRUTURALISMO}

A partir da década de 1960 passaram a ser pensadas, do ponto de vista teórico, novas possibilidades de compreensão da sociedade e dos sujeitos. Perspectivas que se debruçam por sobre questões como a da fabricação dos sujeitos e das relações de poder. Analisadas por meio dos discursos e das tecnologias sociais. Perspectivas como a desenvolvida por Michel Foucault, em especial em sua fase genealógica ${ }^{3}$.

A perspectiva genealógica olha para os sujeitos, para a produção de sujeitos, por meio da consolidação dos poderes, dos saberes e das tecnologias sociais de poder que fabricam estes mesmos sujeitos.

Poderes, saberes e tecnologias sociais (regimes disciplinares) que se consolidam de forma microssocial. Institucional. Geográfica e temporalmente situadas. Avindas,

\footnotetext{
${ }^{3}$ Michel Foucault ficou conhecido, dentre outras coisas, por ter desenvolvido análises sobre a questão do sujeito. Uma análise advinda de seu método arqueológico. Uma análise advinda de seu método genealógico. Uma análise advinda de seu método arque genealógico, voltado a estudar o que chamou de "cuidado de si" ou de processos de subjetivação. 
portanto, de outros lugares que não àqueles ligados às grandes metanarrativas: política, econômica, religiosa. Embora estas, obviamente, também exerçam influência por sobre os indivíduos.

Olhar para a produção de sujeitos, por meio do pós-estruturalismo, exige a compreensão de algumas premissas. Premissas consolidadas a partir de uma gama de intelectuais franceses, que a partir da década de 1960 passam a questionar ideias como a do progresso linear, histórico-social. Premissas que passam a questionar o padrão universal de racionalidade, a ser consolidado por todos os povos. Que questionam a ideia de uma estabilidade estrutural (binária), que perpassaria as diferentes sociedades, garantindo a própria existência da vida social.

O pós-estruturalismo, como teoria, passa a questionar estas e outras premissas advindas do modelo de pensamento até então predominante, ou seja, o estruturalista. $\mathrm{O}$ pós-estruturalismo se desenvolve diante de um quadro social "novo". Advindo da segunda metade do século XX. Por isso, para intérpretes do pensamento pósestruturalista, como Williams (2013):

\footnotetext{
O pós-estruturalismo é pós-marxista... Mas é profundamente devedor de Marx. Todos os pós-estruturalistas... insistiram que eles continuam com o espírito da obra de Marx, como um movimento de esquerda, como um combate pelos marginalizados, pelos explorados e os destroçados. Mas, igualmente, eles resistem a definições fixas da sociedade, das estruturas políticas e dos movimentos revolucionários que provêm do marxismoleninismo ou do maoísmo. O pós-estruturalismo rompe com o marxismo, mas trabalha com Marx (WILLIAMS, 2013:39).
}

Neste sentido, segundo Williams (2013:39), o pós-estruturalismo pertence a um movimento histórico com forte base na filosofia e que busca compreender as novas características do mundo ocidental. Características que se consolidam a partir da década de 1960.

O pós-estruturalismo é um movimento intelectual, advindo da filosofia, que influencia a "literatura, a política, a arte, as críticas culturais, a história e a sociologia" (WILLIAMS, 2013:13). Movimento que se fortalece a partir da análise que certos intelectuais (Michel Foucault, Gilles Deleuze, Felix Guatarri, Jean François Lyotard, etc) fazem de movimentos sociais/culturais como os advindos de maio de 68 . 
Maio de 1968 pode ser interpretado como a mostra de que um diferente tipo de resistência... é possível: ... operando por meio de diferentes estruturas e corpos, abrindo-os a novas possibilidades, libertas de direções ideológicas e ou de uma lógica política estabelecida. Como um herdeiro de 1968, o pósestruturalismo defende a espontaneidade, a fluidez e a abertura, nos movimentos políticos, de resistências (WILLIAMS, 2013:39).

O pós-estruturalismo, entre uma de suas possíveis definições, pode ser considerado, "[...] um conjunto de experimentos acerca de textos, ideias e conceitos que mostram como os limites do conhecimento podem ser atravessados..." (WILLIAMS, 2013:42).

Isto porque o estruturalismo ${ }^{4}$ se manteve, desde o século XIX (a partir do nascimento das Ciências Humanas), passando por boa parte do século XX, como uma forma de racionalidade acadêmico-científica (adstrita a área das ciências humanas), que levava em consideração algumas premissas:

A crença na ordem das coisas (estruturas sociais, por exemplo, compostas por uma lógica interna, autorregulada).

A crença nas Identidades fixas (fossem estas advindas de instituições, de culturas ou de indivíduos), garantidoras de papeis sociais a serem cumpridos, historicamente.

A crença em uma ordem social binária, calcada em formas hegemônicas (dominantes), passíveis de serem compreendidas, desmitificadas e combatidas, rumo a uma nova forma de organização social. Rumo a emancipação ou ao aperfeiçoamento científico, humano, etc.

O pensamento estruturalista, segundo Peters (2000), ancorou-se na ideia de totalidade, de transformação e de auto regulação. Buscou desvendar a lógica, as leis que orientariam/conduziriam as sociedades rumo ao seu futuro. Ao seu progresso, ao seu fim histórico.

\footnotetext{
O conhecimento estruturalista é aberto a mudança quando as estruturas observadas mudam. Entretanto, a despeito desta abertura à mudança, ao notar um padrão repetitivo de signos o cientista estruturalista espera alcançar alguma compreensão segura (WILLIAMS, 2013:14).
}

\footnotetext{
${ }^{4}$ Como estruturalismo podemos entender uma forma de olhar o social que se ancora em leis ou na lógica interna, autorreferente, que perpassaria as sociedades. A estruturalismo se ancorou em premissas como a da totalidade, transformação e auto-regulamentação que, para essa corrente, formataria os sistemas e ou as estruturas sociais.
} 
O pensamento estruturalista buscou estabelecer uma forma de cientificidade, para as Ciências Humanas, capaz de apreender a lógica estrutural que perpassaria o movimento histórico e social. Palavras como leis, verdade, funcionalidade das instituições e ou dos sistemas, desenvolvimento - linear - histórico, fim histórico, emancipação e progresso fizeram/fazem parte importante do vocabulário estruturalista.

O mundo observado pelos estruturalistas foi o mundo advindo da modernidade, calcado na supremacia europeia, na perspectiva e ou na crença diante do progresso econômico social. Na busca pela verdade universal a ser liberta das amarras que a estariam escravizando.

Cabe notar que assim como o estruturalismo representa as correntes de pensamento que surgem no século XIX e que buscam tornar compreensível o mundo moderno (europeu, urbano, industrial, antropocêntrico - embasado em formas de racionalidade cada vez mais científicas - e menos religiosas); o pós-estruturalismo surge na segunda metade do século XX de modo a compreender o mundo pós-guerra fria (organizado na dualidade entre URSS versus EUA), ou seja, o mundo que entra na globalização (organizada por meio da "vitória" do capitalismo por sobre o comunismo e por meio da "separação" entre campo econômico - por conta do capitalismo financeiro - e campo político - Estados-nação).

O pós-estruturalismo busca compreender as novas identidades (chamadas, por autores como Zigmunt Bauman, de identidades líquidas), que surgem e que passam a ter voz e a contestar as identidades tradicionais, fixas (tais como a identidade patriarcal, masculina, que dominara, até então, as relações adstritas à esfera familiar).

Busca compreender as novas formas de racionalidade (e, por vezes, de irracionalismos) que despontam desde o século XX, por meio da barbárie encabeçada, na Europa, pelos regimes totalitários (nazismo, fascismo, stalinismo/leninismo, maoísmo, etc). Diga-se de passagem, à direita e à esquerda do espectro político. Mostrando que o mundo não é dominado, de forma crescente, pela razão científica, ponderada. Mas, por vezes, por impulsos e sentimentos destrutivos e ou destituídos de uma razão que se encaixe em uma ideia de evolução humana, linear. Mostrando, ainda, que as formas de racionalismo - quando absolutizadas - tendem a se tornarem totalitárias. 
Os pós-estruturalistas, tal como aponta Williams (2013:29), simplesmente identificam - por vezes, de forma estarrecedora - que os sonhos advindos da modernidade ${ }^{5}$ não foram atingidos na sua totalidade.

Que estes sonhos, como se refere Souza (2016) ao parafrasear Bauman, por vezes, foram frustrados. Aparecendo, diante de nós, como o despertar maldito de um sonho colorido. Justamente pelo fato de não se concretizarem como esperado. Por isso, a pós-modernidade ${ }^{6}$ apresenta-se como uma tomada de consciência social diante dos limites e ou do 'fracasso' das promessas consolidadas desde a modernidade.

Deste modo, o

pós-estruturalismo não é uma forma de anti-humanismo ou de irracionalismo. É uma prática que visa mostrar os limites e problemas do humanismo e do racionalismo, embora mantendo seu viés progressista (WILLIAMS, 2013:29).

A modernidade se baseou, em grande medida - assim como o estruturalismo na crença da força benéfica da ciência. Garantidora do futuro e do progresso. Garantidora da ordem, da estabilidade e da felicidade humana.

Processo que, para seu estabelecimento, careceria de um movimento anterior, calcado em um sujeito universal, consciente, capaz de chegar a verdade das coisas e de transformar a vida, dando-lhe uma direção e um sentido preciso.

Por isso, para os modernos, e para os estruturalistas a história tem uma linearidade latente. Passível de ser controlada e aperfeiçoada.

De forma mais importante, a modernidade implica o mito, que ela constrói sobre si própria, de que é capaz de criar, de alguma forma, a partir da força histórica, de seu movimento e de sua trajetória, suas próprias orientações normativas (PETERS, 2000: 66).

\footnotetext{
${ }^{5}$ Supremacia da razão e da ciência por sobre os obscurantismos e formas de ignorância humanas; concretização de projetos econômico, políticos e sociais que sejam capazes de levar o progresso para todos; a propensão humana para o bem e para estabelecer processos de justiça social amplos e duradouros; a capacidade humana para alcançar a verdade por trás dos fenômenos sociais.

${ }^{6}$ Pós-modernidade é o nome dado às transformações culturais, sociais - mas também econômicas - que surgem a partir das décadas de 60 e 70 do século XX, no ocidente.
} 
Já na pós-modernidade ${ }^{7}$ despontam questionamentos sobre a ideia de linearidade histórica. Por conta das inúmeras leituras (localizadas e baseadas nas distintas etnias, nas distintas religiões, nas distintas culturas e modos de ver a vida) que passam a ocupar o mundo globalizado. Leituras que nascem de relações que se entrecruzam, no mundo globalizado. Mas que, ao mesmo tempo, encontram dificuldades para estabelecerem uma visão única, consensual, acerca do homem e da vida social.

A própria crença, advinda da modernidade, de que o progresso, a evolução (daí termos como "progressista" aparecerem com força, na modernidade) e o humanismo ${ }^{8}$ fossem coisas positivas, per si; passa a ser contestada na pós-modernidade.

A ideia de que o sujeito (visto como universal, centrado, estável e autoconsciente) seria capaz de construir um conhecimento sobre o mundo - verdades sobre este mundo e sobre si mesmo - são, paulatinamente, substituídas por leituras localizadas (por aquilo que se pode chamar de "pontos de vista").

Na esteira desta "crise", desta mudança, advinda da segunda metade do século XX, o pensamento pós-estruturalista

\begin{abstract}
desenvolve uma série de diferentes métodos e abordagens como, por exemplo a arqueologia, a desconstrução, cada um dos quais funcionando de acordo com sua própria lógica, mas, considerados em seu conjunto, tendendo a enfatizar noções de diferença, de determinação local, de rupturas ou descontinuidades históricas, de serialização, de repetição e uma crítica que se baseia na ideia de "desmantelamento" ou de "desmontagem" (leia-se 'desconstrução"). (PETERS, 2000: 37.
\end{abstract}

O pós-estruturalismo levou estas questões e transformações sociais em consideração, de modo a criar suas formas intelectuais de ler o social.

Por meio de novas formas de compreender estas novas realidades, os pósestruturalistas fizeram novas perguntas, buscaram novos métodos de análise do social. Assim, desenvolveram novas perspectivas, indo além daquelas explicações oferecidas até então, para dar conta de uma realidade, na qual, segundo Williams (2013:42), os discursos que antes tendiam a encontrar a verdade final agora subsistem, em grande

\footnotetext{
${ }^{7}$ Período histórico também chamado, por alguns intelectuais, de modernidade tardia (Anthony Giddens) e de modernidade líquida (Zigmunt Bauman).

8 “[...] que tinha como pressuposto a existência de um eu estável, coerente, apreensível, capaz de desenvolver um conhecimento sobre si próprio e sobre o mundo por meio da razão" (PETERS 2000, p. $35)$.

Programas de Pós-Graduação em Ciências Sociais e Filosofia - UNIOESTE - Rua da Faculdade 645. Toledo - PR. CEP 85.903-000 Email: revistaalamedas@gmail.com
} 
medida, como perspectivas. Ao avesso da ideia absoluta de verdade e de ordem final a ser alcançada.

"As obras pós-estruturalistas convocam variedades de interpretações diferentes e resistem a significados últimos e comunicáveis universalmente" (WILLIAMS, 2013: $32)$.

Um aspecto importante, advindo das perspectivas pós-estruturalistas, é aquele atrelado ao seu poder de resistir e trabalhar contra verdades e oposições classicamente estabelecidas (WILLIAMS, 2013:17).

\footnotetext{
No pós-estruturalismo a vida não deve ser definida apenas pela ciência, mas pelas camadas de história e criações futuras capturadas em sentido mais amplo da linguagem, do pensamento e da experiência (WILLIAMS, 2013:34).
}

Como a vida não cabe, integralmente, nas explicações cientificas. Como a vida é movida por uma infinidade de forças e relações, que contribuem para sua dinâmica estando, estas forças e relações, diretamente ligadas a seus valores e contextos específicos - os pós-estruturalistas lembram, então, que as próprias teorias que buscam atingir a verdade absoluta, plena, da vida - notadamente nas ciências humanas - não são mais do que, também, crenças acerca da verdade. Crenças a respeito da capacidade que teríamos de chegarmos a verdade final, definitiva, sobre nós mesmos e sobre a vida.

Deste modo, "o pós-estruturalismo se opõe a verdades fundantes e a metas (ou mesmo direções) finais" (WILLIAMS, 2013:98). Analisa as questões sociais. A produção dos sujeitos. Mas sem ter como pano de fundo a tentativa de chegar a verdade final, completa acerca da vida. Acerca dos sujeitos.

\section{O PÓS-ESTRUTURALISMO DE MICHEL FOUCAULT: A CONSTRUÇÃO DOS SUJEITOS}

O pós-estruturalismo foucaultiano, segundo autores como Williams (2013:153), livra-se da ilusão de que há uma verdade final a ser atingida, por meio da análise social, no que se refere ao sujeito, à história ou à consciência humana. Para Foucault "somos 
historicamente condicionados, mas assumimos nosso lugar em um sistema aberto e contingente" (WILLIAMS, 2013:155).

A partir disso, Foucault traz uma profunda contribuição para pensarmos os processos de subjetivação, ou seja, de construção/produção dos sujeitos. Uma vez que é o tema do sujeito que mobiliza os estudos de Foucault, conforme Fonseca (2003:24) aponta.

A questão da produção dos sujeitos, de como somos levados a sermos sujeitos. As formas de produção dos sujeitos (via poderes e saberes) são temas retratados por Foucault, em sua obra.

Foucault, ao buscar a compreensão sobre o sujeito constrói uma perspectiva, segundo Veiga-Neto (2016:16), que dá as costas a metanarrativa iluminista, que propunha a existência de um sujeito universal, desde sempre aí, que pode ser desvelado e descoberto e que preexiste ao mundo social. Capaz, por isso mesmo, de conhecer a verdade fenomênica do mundo.

Em Foucault os sujeitos são produzidos por meio de processos (tecnologias sociais). Notadamente por meio de dispositivos (estratégias, consolidadas pelas instituições, por meio dos saberes que ali se encontram; que se voltam para a subjetivação - produção - dos indivíduos que passam pelas instituições).

Foucault produziu uma histórica acerca dos diferentes modos de subjetivação. Levando em conta relações de poder (e nunca "o poder", tomado como substância ou como refém das relações jurídicas e ou econômicas); saberes locais (desenvolvidos nas instituições); uma relação de si para consigo mesmo (tema a qual Foucault chama de processo ético).

A questão das asserções de verdade, ou seja, a busca pela legitimação dos discursos, colocados em debate, na arena política; é outro ponto levado em consideração por Foucault. Até porque percebe que os sujeitos estão dispostos, via de regra, diante de discursos que buscam legitimar ações por sobre estes mesmos sujeitos.

Este processo, envolto por ações institucionais (poderes em ação); por saberes que se acercam dos indivíduos e grupos, buscando "conduzir" suas ações; por singularidades históricas, morais e situacionalmente localizadas acabaram por caracterizar uma forma de olhar para o social, denominada de método genealógico, por Foucault. 
Conforme Revel (2005:52), aponta:

\begin{abstract}
A genealogia trabalha, portanto, a partir da diversidade e da dispersão, do acaso dos começos e dos acidentes: ela não pretende voltar no tempo para restabelecer a continuidade da história, mas procura, ao contrário, restituir os acontecimentos na sua singularidade (REVEL, 2005:52).
\end{abstract}

Este esforço de Foucault, ao tentar compreender como os saberes locais, descontínuos e em busca de legitimação se consolidam - a partir da produção discursiva de verdades que se voltam aos indivíduos, produzindo-os - gerou a genealogia.

Genealogia que, segundo Foucault, pode ser entendida, ainda (do ponto de vista de uma ação engajada, politica):

\begin{abstract}
Não como um empirismo ou um positivismo, no sentido habitual do termo. Mas como um modo de ativar saberes locais, descontínuos, desqualificados, não legitimados, contra a instância teórica unitária que pretenderia depurálos, hierarquiza-los, ordená-los em nome de um conhecimento verdadeiro, em nome dos direitos de uma ciência detida por alguns. [...] Não de trata da insurreição dos saberes antes de tudo contra os conteúdos, os métodos e os conceitos de uma ciência, mas de uma insurreição dos saberes antes de tudo contra os efeitos de poder centralizadores que estão ligados a instituição e ao funcionamento de um discurso cientifico organizado no interior de uma sociedade como a nossa (FOUCAULT, 2017: 268)
\end{abstract}

\title{
A GENEALOGIA FOUCAULTIANA
}

Segundo Veiga-Neto (2016:55), na fase genealógica ${ }^{9}$ Foucault vai buscar compreender como os saberes se consolidam nas instituições. Como são referendados por meio dos poderes gerenciados dentro das instituições.

Como este processo de saberes e poderes atuam, no sentido de produzir determinados tipos de sujeitos.

A genealogia Foucaultiana reforça a ideia de que é preciso descer aos "porões", ao subterrâneo da história para que se supere as grandes metanarrativas, tais como as advindas dos campos religioso, jurídico e ou político.

\footnotetext{
${ }^{9}$ A obra de Michel Foucault e dividida entre os especialistas, segundo VEIGA-NETO (2016, p. 35) em três fases, fase arqueológica, genealógica e fase ética ou I, II e III fase. Esta divisão obedece critérios metodológicos e cronológicos. Em cada fase Foucault norteou seu trabalho com um problema principal associando uma determinada metodologia para resolve-lo. 
Metanarrativas que foram consolidadas, com o passar do tempo, e que parecem dar um sentido histórico, uma ordem gnoseológica e um sentido moral/final aos fatos sociais. Consolidando, ao mesmo tempo, asserções de verdade sobre a história, sobre os sujeitos, sobre as sociedades.

Foucault, com sua genealogia, constrói um tipo diferente de história social.

\begin{abstract}
A genealogia faz um tipo especial de história. Como a palavra sugere, trata-se de uma história que tenta descrever uma gênese no tempo. Mas, na busca da gênese, a história genealógica não se interessa em buscar um momento de origem, se entendermos origem no seu sentido "duro", isso é, como uma solenidade de fundação em que "as coisas se encontravam em estado de perfeição", ou se a entendermos como "o lugar da verdade" (VEIGA-NETO, 2016: 56).
\end{abstract}

O que Foucault propõe, com sua fase genealógica, é compreender a história em construção (história localizada, situacionada, passível de transformação). E não a origem histórica das coisas ou o fim histórico que, porventura, estaria a nos esperar.

\begin{abstract}
Em vez de acreditar na metafísica o genealogista deve escutar a história em seu próprio funcionamento, em sua própria materialidade. Assim procedendo, ele aprende que "atrás das coisas há 'algo inteiramente diferente': não seu segredo essencial e sem data, mas o segredo que mostra que elas são sem essência, ou que sua essência foi construída peça por peça a partir de figuras que lhe eram estranhas". (VEIGA-NETO, 2016:56-57).
\end{abstract}

Ao olhar para história desta forma, Foucault, segundo Veiga-Neto (2016:57), não buscou compreender os fatos sociais por meio de possíveis pontos de apoio, mas indo ao próprio acontecimento histórico (localizado), de modo a perceber, ao redor deste, os movimentos (dos poderes e dos saberes) que o engendram e o alimentam. Num emaranhado de ações vivas, dispostas por meio de estratégias institucionais/situacionais.

Assim, pode-se entender a genealogia como um conjunto de procedimentos úteis não só para conhecer o passado, como também, e muitas vezes principalmente, para nos rebelarmos contra o presente (VEIGA-NETO, 2016:59).

Partindo do pressuposto de que "as grandes narrativas são, pois, histórias que as culturas contam sobre suas próprias práticas e crenças, com a finalidade de legitimá-las” (PETERS, 2000:18); a genealogia Foucaultiana, enquanto diagnóstico do presente, se 
utiliza da história para mostrar "a contingência do que é o nosso presente e daquilo que nele somos" (GARCIA, 2002:18).

A analítica dos dispositivos (poderes institucionais em ação, via estratégias e saberes localmente consolidados), em Foucault, nos leva a prestar atenção nos detalhes institucionais.

Pequenas astúcias, dotadas de um grande poder de difusão, arranjos sutis, de aparência inocente, mas profundamente suspeitos, dispositivos que obedecem a economia inconfessáveis, ou que procuram coerção sem grandeza [...] (FOUCAUL, 2014:136).

Foucault procura construir uma relação entre as relações de poder e a construção de saberes, por meio da ação que estas processam, no sentido da disciplinarização dos corpos/comportamentos.

"O objetivo de Foucault é traçar uma genealogia das relações entre poder e o saber, para mapear a ontologia do presente, em termos do ser-poder" (VEIGA-NEGO, 2016: 65). Mostrando, assim, que processos de disciplinarização (controle) e docilização (estimulação) dos corpos, a partir do advento da sociedade disciplinar (capitalista) se faz muito mais por meio de estratégias sutis, político-econômicas; do que por meio do terror, da alienação e ou da dominação explícita.

Por meio desta perspectiva Foucault se importa em compreender como chegamos a ser quem somos. Ao mesmo tempo, o autor vislumbra as possibilidades que os indivíduos, os grupos sociais têm, no sentido de abrirem espaços de liberdade as contingências, diante das quais se encontram.

A faze genealógica foucaultiana pode ser entendida, portanto, como um método para compreender as formas de ação, adotadas pelos homens, diante dos homens (neste sentido, é o estudo da construção das condutas que visam conduzir/controlar - e não, necessariamente, aniquilar, violentar, oprimir - outras condutas).

Na genealogia busca-se apreender os caminhos, os saberes e as práticas (poderes em ação) adotados institucionalmente.

Busca-se compreender a ação dos sujeitos, por meio do planejamento desta. $\mathrm{O}$ que se dá, via de regra, por meio da produção de processos (valores, regras, percepções 
de como as coisas são ou devem ser) que capturam, dividem e classificam os indivíduos e grupos.

\section{CONCLUSÃO}

Concluímos por meio de uma perspectiva pós-estruturalista que as novas realidades sociais da sociedade de nos permeia, exigem novos olhares e novas esforços para sua compreensão. Nesta direção, o pós-estruturalismo pode nos oferecer alguns instrumentos para a construção destes novos olhares.

Da mesma forma, entendemos que a obra de Michel Foucault oferece uma gama de possibilidades para estas compreensões, em especial no que tange a discussão sobre a fabricação dos sujeitos, as novas dinâmicas das relações de poder saber as quais estes sujeitos sociais são construídos.

\section{BIBLIOGRAFIA}

BAUMAN, Zygmunt. Modernidade líquida. Tradução Plínio Dentzien. - Rio de Janeiro: Zahar, 2001.

FOUCAUlT, Michel. Microfísica do Poder. Organização e tradução de Roberto Machado. Rio de Janeiro: Edições Graal, 1979.

FOUCAULT, Michel. Vigiar e punir: nascimento da prisão. Tradução de Raquel Ramalhete. 42. Ed. Petrópolis, RJ: Vozes, 2014.

FOUCAULT, Michel. História da Sexualidade 1: A vontade de saber. Tradução de Maria Thereza da Costa Albuquerque e J. A. Guilhon Albuquerque. $6^{\circ}$ ed. Rio de Janeiro/São Paulo, Paz e Terra, 2017.

FONSACA, Márcio Alves da. Michel Foucault e a constituição do sujeito. São Paulo: EDUC, 2003

GARCIA, Maria Manuela Alves. Pedagogia crítica e subjetivação: uma perspectiva foucaultiana. Petrópolis, RJ: Vozes, 2002.

GARCIA, Maria Manuela Alves. O intelectual educacional e o professor crítico: o pastorado das consciências. Currículo sem Fronteira, v.2, n.2, pp.53-78, Jul/Dez 2002.

GOHN, Maria da Glória. Sociologia dos movimentos sociais. 2. Ed. - São Paulo: Cortez, 2014. - (Questões da nossa época; v. 47). 
HALL, Stuart. A identidade cultural na pós-modernidade. Tradução Tomaz Tadeu da Silva, Guaraciara Lopes Louro. 10 ed, Rio de Janeiro: DP\&A, 2005.

LYOTARD, Jean-François. A condição pós-moderna. Tradução: Ricardo Corrêa Barbosa; posfácio: Silviano Santiago. $7^{\circ}$ ed. Rio de Janeiro: José Olympio, 2002.

MACHADO, Roberto. Nietzsche e a Verdade. 3 ed. Ver. Rio de Janeiro/são Paulo: Paz e Terra, 2017.

MOSÉ, Viviane. O homem que sabe: do homo sapiens à crise da razão. Rio de Janeiro: Civilização Brasileira, 2011.

MOSÉ, Viviane. Nietzche Hoje: sobre os desafios da vida contemporânea. Petrópolis, RJ: Vozes, 2018.

NOGUEIRA-RAMÍREZ, Carlos Ernesto. Pedagogia e governamentalidade ou Da Modernidade como uma sociedade educativa. Autêntica Editora, 2011

MORAES, Roque; GALIAZZI, Maria do Carmo; RAMOS, Maurivan Güntzel. Aprendentes do aprender: um exercício de análise textual discursiva. Indagatio Didactica, v. 5, n. 2, p. 868-883, 2013. Disponível em: <http://revistas.ua.pt/index.php/ID/article/view/2496/2364>. Acesso em: 30 de junho de 2019.

REVEL, Judith. Michel Foucault: Conceitos essenciais. Tradução Maria do Rosário Gegolin, Nilton Milanez, Calos Piovesani. São Paulo: Claraluz, 2005.

SILVA, Tomaz Tadeu da. Identidade e diferença: a perspectiva dos estudos culturais. (Org.). Stuart Hall, Kathryn Woodward. 15. Ed. Petrópolis, RJ: Vozes, 2014.

SOUZA, Sonielson Luciano de. Pondé: dúvida e superficialidade nos vínculos da pós-modernidade. $2016 . \quad$ Disponível em: $<$ https://encenasaudemental.com/comportamento/insight/ponde-duvida-esuperficialidade-nos-vinculos-da-pos-modernidade/>. Acesso em: 29/06/2019

PASQUALINI, Juliana Campregher; Teixeira, Lucas André; Agudo, Marcela de Moraes. Pedagogia histórico-crítica: legado e perspectivas. Uberlândia: Navegando Publicações, 2018.

PETRES, Michel. Pós-estruturalismo e filosofia da diferença. Tradução de Tomaz Tadeu da Silva. Belo Horizonte: Autêntica, 2000.

PRESTES, M. L. M. A Pesquisa e a construção do conhecimento científico: do planejamento aos textos, da escola à academia. 4. ed. São Paulo: Rêspel, 2012. 
VEIGA-NETO, Alfredo. Foucault e a Educação. Belo Horizonte: Autêntica Editora, 2016.

WILLIAMS, James. Pós-estruturalismo. Tradução de Caio Liudvik. 2 ed. Petropolis, RJ: Vozes, 2013. 